\title{
Embedded assumptions in design and Making projects with children
}

\author{
Leena Ventä-Olkkonen \\ Interact research unit, University of Oulu \\ Heidi Hartikainen \\ Interact research unit, University of Oulu
}

\author{
Marianne Kinnula \\ Interact research unit, University of Oulu \\ Netta livari \\ Interact research unit, University of Oulu
}

\begin{abstract}
Previous literature highlights the importance of teaching children design and Making skills. However, there are fundamental differences in projects engaging children in design and Making, concerning the objects and motives of design. They vary depending on whether one emphasizes participatory design, user centered design, Making philosophy or entrepreneurship education, among others. In the first two, the emphasis is on the appreciation and engagement with the user, who is seen as separable from the designer. The third one often starts with solving one's own problems while the fourth one prioritizes the customer. In this paper, we analyze the existing literature and three of our own design and Making projects with children. We reveal diversity in the projects reported in the literature and challenges among children in our projects in understanding the design goals and practices, particularly relating to designing for oneself versus designing for others. We propose a categorization for mapping and managing this diversity.
\end{abstract}

\section{CCS CONCEPTS}

- Human-centered computing $\rightarrow$ Interaction design; Empirical studies in interaction design; • Social and professional topics $\rightarrow$ Professional topics; Computing education; K-12 education.

\section{KEYWORDS}

Making, Digital Fabrication, Design, Children, School, Business, User need, User centered design, Participatory design, FabLab

\section{ACM Reference Format:}

Leena Ventä-Olkkonen, Marianne Kinnula, Heidi Hartikainen, and Netta Iivari. 2020. Embedded assumptions in design and Making projects with children. In 32nd Australian Conference on Human-Computer Interaction (OzCHI '20), December 02-04, 2020, Sydney, NSW, Australia. ACM, New York, NY, USA, 11 pages. https://doi.org/10.1145/3441000.3441077

\section{INTRODUCTION}

This paper is set to explore design and Making as intermingled with education of children. It has been acknowledged that engaging in different participatory design and Making activities has the potential to teach children valuable 21 st century skills, such as

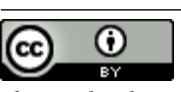

This work is licensed under a Creative Commons Attribution International 4.0 License.

OzCHI '20, December 02-04, 2020, Sydney, NSW, Australia 2020. ACM ISBN 978-1-4503-8975-4/20/12.

https://doi.org/10.1145/3441000.3441077 critical thinking, problem solving, creativity, teamwork, and communication (e.g. [12], [2], [36]). Previous literature has introduced numerous design and Making projects conducted with children in schools as well as in informal learning settings [see 56]. In addition to the actual Making part, these projects often include distinct phases for design and ideation, and because of this, they don't teach children only Making skills e.g. [6], [5] but also designerly thinking and user-centered or participatory design skills [25], [42]. However, user-centered design, participatory design, and Making have somewhat differing background philosophies and foci, particularly related to who is the target of design/Making. While human or user-centered design and participatory design focus on appreciating and engaging the user, seen as separable from the designer skills wise (see e.g. [18], [33], [19], [40], [43]), the philosophy behind Maker movement underscores Do-It-Yourself (DIY) approach - being able to make and modify things yourself for your own use, with a strong community aspect though (e.g. [15], [45]). When educating future designers and Makers, for user-centered designers empathy towards others is considered essential [30], and in participatory design ethical responsibilities of designers towards users have always been in the forefront (see e.g. [43]), whereas Making in education is more focused on Makers' technical skills and fulfilling Makers' own needs (e.g. [15], [45]).

We argue that for the Human-Computer Interaction (HCI) community in general and for the Child-Computer Interaction (CCI) community in particular, it is pivotal to reflect on these differences when engaging with children in design and Making projects. The existing literature has not discussed these fundamental differences in depth, even if a body of research on design and Making with children in the context of their education has already been published. We maintain it is important for the researchers to be aware, understand, and reflect on this variety when educating children with projects that combine design and Making with children. Because of this, we address in this paper the problem of embedded assumptions in methodological choices in design and Making projects with children in the context of their education. In other words, we ask: who are we actually designing for in design and Making projects with children in the context of their education, and what do we wish to teach to children through design and Making?

In this paper, we first discuss the existing literature addressing design and Making with children, concentrating on the variety involved in these studies. Then, we introduce the research design and methodology involved in this study. This study represents qualitative research, in which we explore a series of design and Making projects conducted in three different schools with 7-15-year-old children. We present and analyze the field study and design and 
Making tasks the children participated in during the projects, and their outcomes. In our analysis, we particularly focus on challenges encountered. Based on the existing literature and our empirical insights, we present a categorization - mapping the diversity in the field - that should be helpful for researchers and practitioners conducting design and Making projects with children in education context: it should enable them to make conscious choices on who to design for and what to aim to teach to children in the projects, helping in planning the activities as well as positioning the research. The categorization reveals underlying assumptions concerning what we are actually teaching children through design and making projects. This study focuses on technology and STEM education of children, addressing the educational/learning goals in particular, leaving out an examination of children's actual learning processes and outcomes.

\section{ACCESSIBILITY DESIGN AND MAKING - A VARIETY IN THE MAKING}

\subsection{User-centered and Participatory Design - Designing for and with Others}

Already since the 1980s, the significance of user and humancentered design (HCD) has been emphasized in the HCI field while designing products and services. It has been underscored that designers need to understand the people they are designing for, they need to engage users in the design process to get their feedback on the design solution, and they need to iterate the design solution based on users' feedback [18], [33]. Participatory Design (PD) tradition, moreover, has for even longer stressed the importance of users' active engagement in the design process: users should have a voice in the design process affecting their lives, and therefore PD sessions need to be organized in a way that enables users' genuine participation and influence [19], [40], [43].

Such developments have been highly influential in CCI research. Children have been invited into the design process as informants, testers, and design partners for decades already, at least for indicating their needs and providing feedback on the evolving design, if not for engaging as equal design partners in a participatory design process [10], [11], [13], [21], [37], [38], [39], [44]. Druin, but also many after her, have been influenced by the Scandinavian PD tradition and emphasized that projects need to be organized in a way that children's participation as equal partners and their influence in the design are ensured (e.g. [11], [20]). Some researchers have also underscored the political aspects of Scandinavian PD in their work with children, arguing for empowerment of children and requesting even more powerful and influential roles for them in the design process, such as the protagonist role (see e.g. [23], [25]).

Much of the previous research, albeit valuable, has invited children to take part in the design process as 'experts of being a kid', representing his or her own viewpoint in the design process. In the literature, few studies have specifically considered how to enable children to start acting as designers - responsible for the design work and designing for someone else, not only for oneself. In most of the studies, children's personal development as designers is not considered; it seems it is implicitly assumed that there are adult designers - human- or user-centered or participatory ones - responsible for the design process, inviting and facilitating children's participation. However, some CCI studies can be found that specifically emphasize offering children designer skills and competencies as part of their education (see e.g. [25], [29], [42]), showing an emerging interest on the topic. There are CCI studies in which children have been engaged in conducting user or field studies, including interviews and observation, with the aim to understand user needs, not only their own needs as users (e.g. [1], [10], [25], [42], [50]). Such information has been collected by children acting as designers themselves, potentially as part of an intergenerational design team. There is also research aiming at arousing empathy in children as part of the design process with different kinds of thought exercises, storytelling and reflection ( [52], [53]). Empathy towards users is generally considered a cornerstone of human- or user-centered design. The studies show that children developed empathy towards fictional characters they were designing for, acting as protagonists in the stories. In one study children acted as designers of games as well as arranged usability testing sessions into which they invited other children, to gain feedback for the improvement of the games, clearly adopting a designer position [29].

All this indicates that in some CCI studies the topic of adopting a designer position and designing for someone else has been acknowledged: there is an extensive body of research discussing design with child design partners as well as a relatively limited yet emerging body of research discussing the challenges and practices involved in inviting children to develop their designer skills and competencies and to design for someone else. Next, this literature base is contrasted with the literature addressing Making.

\subsection{Maker movement - DIY for yourself}

In the Maker movement, democratizing of innovation is in the focus: ordinary people acquiring and using skills that enable them to innovate, design, engineer, and program personally meaningful objects for their own use, solving their problems (see e.g. [15], [45]). Open source software and hardware, and hacker and doit-yourself (DIY) movements form the background to the Maker movement, emphasizing people taking their own initiative in the creation of software, hardware, and other tools for serving their personal needs and interests. Making, however, is not only a solo activity entirely focusing on an individual's interests and needs, but there is a strong communal aspect involved, too. Important part of the Maker movement is sharing knowledge with others, giving to others what one has made, participating in and contributing to the wider community and helping each other (see e.g. [3], [8], [22], [26] [27], [31], [35], [47]). However, the very basic idea of Making is individual-oriented: "Making is fundamental to what it means to be human. We must make, create, and express ourselves to feel whole. There is something unique about making physical things. These things are like little pieces of us and seem to embody portions of our souls." [22].

The maker movement has made its way rapidly into education contexts: it is seen to have a remarkable potential to transform STEAM (science, technology, engineering, arts, and mathematics) education (see e.g. [35]). Besides learning how to design and make products per se, Making has potential in teaching children also other valuable skills and mindsets needed in the 21st century, such 
as critical thinking, problem solving, creativity, teamwork, and communication skills (see e.g. [2], [12], [36]). Integrating Making related activities in education has been embraced by researchers and practitioners alike [2], [6].

CCI researchers have also embraced the Maker movement and advocated children engaging in Making (e.g. [2], [6], [9], [23], [25], [26] [27], [42], [46], [55], [56]). However, there is quite a lot of variety in these studies regarding their goals and practices. Clearly differing learning goals and subjects have been associated with the studies. In some of them, the priority has been in children's technology or STEM education and in developing children's Making skills (e.g. [5], [6], [27]) while in others the emphasis has rather been on design education and a creative, user-centered design process around Making activities has been emphasized (e.g. [25], [42]) In many of the studies children have been designing and Making personally meaningful objects and tools (e.g. [9], [23], [27]) while in others the objects under development have been integrated with science education, addressing different science subjects (e.g. [6]). Moreover, in others, social science related topics such as community development (e.g. [46], [55]) and solving of societally relevant problems ([2], [25], [42]) have been underscored. We think that addressing community or societally relevant problems include necessarily designing for someone else, not only for the self. However, so far CCI studies have not reflected on the fundamental differences between design and Making in education in terms of whom the work is to serve and what we are teaching to children about design and Making along the way.

\subsection{Making for business and the customer}

To show even more variety within the Maker movement, we point out an entrepreneurial vision of Making that has been contrasted with a hobbyist one [32] discussed so far in this paper. Within the entrepreneurial vision, the Maker movement has been seen as a powerful enabler for innovation [8] and as related to the user innovation concept (see [54]). Making is closely connected with business and seen as a key to entrepreneurship ([4], [32]). A lot of business has been growing around Making, Maker fairs and Makerspaces with a number of established companies and a stream of startups emerging [32], the entrepreneurial action of the Makers ranging from hobbyist to small business owners, growth entrepreneurs, and corporate innovators [4]. Maker movement may influence entrepreneurship through different channels: Makers may accidentally find out that their solutions are of interest to a wider community, enabling building business around them. Moreover, rapid prototyping is at the heart of Making, perfectly serving new product development and building of new business. In addition, the wider network involved in Making may be purposely utilized for idea generation and innovation in business. [4], [51]. For existing businesses, the Maker community has been argued to be both a source for new talents and new ideas to be exploited in business [8], and the multidisciplinary nature of Makerspaces makes them a valuable source for new ideas, compared with a traditional business environment [41].

Some have already embraced Making as a source for new businesses and entrepreneurship in the context of children's education.
They see it as a possibility for children to grow to 'digital innovators of future' who can change the world through their skills [23]. For this end, efforts combining Making and early entrepreneurial education, even if still relatively rarely reported, have emerged, Unterfrauner et al. [49] and Fraunhofer et al. [14] reporting on such a project. They argue for the pedagogical value of Making in early entrepreneurship education [16]. In this, children should learn essential abilities, useful in their future education and practices, as it is many years before they possibly end up using those abilities for professional purpose [16], [34]. The focus of entrepreneurial education and entrepreneurship in general is largely about creating such business where a customer is willing to pay for the value added by some products or services. Therefore, the focus of entrepreneurial Making widens designing for oneself, or a 'user', to a new concept, a 'paying customer.' Such a shift implies again diversity in terms of what children are being taught and the ethical and political implications. Yet, these aspects are not discussed in the literature.

\section{METHODS AND MATERIALS}

This study represents qualitative, interpretive research, which does not involve formal propositions, quantifiable measures of variables or hypothesis testing [58], but instead qualitative researchers studying "things in their natural setting, attempting to make sense of, or to interpret, phenomena in terms of the meanings people bring to them" ( [59]: 3). In this study, we explore meanings making within our design and Making projects with children that we have organized in collaboration with their teachers.

In this section, we introduce the three design and Making projects conducted in three public schools in Oulu area in Finland (summarized in Table 1), through which we illustrate the challenges related to design and Making activities with children. The presented projects proceeded the arguments elaborated in this paper but the general learning goal in all these projects was for children to learn design and Making skills. The children involved in the projects were selected by volunteering teachers who were willing to experiment with the design and Making project as part of their teaching. Teachers indicated four classes of children to work with. Teachers from the 1st grade, a special need class (project A), and 4th grade (project B), and English and social studies teachers with 9th grade class (project C) participated the project. When conducting any research with children, one must carefully consider the ethical issues. Guidelines of the Ethics committee of human sciences of University of Oulu were consulted. As this research concerned minors, it was essential to gain informed consent both from the children and their guardians. All children received an informed consent form giving information on the research and asking whether the children themselves were willing and whether the guardians allowed the participation of the children in the study. 61/81 children returned the consent to take part in the study. In all projects, all the children participated in the activities as part of their normal teaching, but material was collected only from the children with informed consent. Ages of the participating children varied between 7 and 15 years. All projects were conducted in 2018.

Project A was conducted with a combined group of 1st graders and special need class (consisting of pupils from 3rd and 5th grades) and Project B was implemented with a class of 4 th graders. These 
Table 1: Summary of the setups of three design and making projects with children.

\begin{tabular}{llll}
\hline Project & A & B & C \\
\hline Participants n & $36\left(28^{a}+8^{b}\right)$ & 26 & 27 \\
Grade (age) & $1 \mathrm{st}(7-8 \mathrm{y})^{a} \&$ 3rd-5th $(9-11 \mathrm{y})^{b}$ & 4 th $(10-11 \mathrm{y})$ & 9 th $(14-15 \mathrm{y})$ \\
Sessions n & 5 & 6 & 10 \\
Themes of the & Field work (observation, cultural & Field work (observation, interviews, & Ideation, Background research, \\
workshops & probes), Ideation, Design (concepting, & cultural probes), Ideation, Design & Design, Making, Presenting \\
& 3D modelling), Programming & (concepting, 3D modelling), & business ideas \\
Analyzed data & Field notes, photos and videos, & $\begin{array}{l}\text { Programming } \\
\text { inteld notes, photos and videos, }\end{array}$ & $\begin{array}{l}\text { Field notes, pupils' presentations, } \\
\text { interviews }\end{array}$ \\
\hline
\end{tabular}

two projects followed the same structure. Workshops were conducted in a weekly basis during five (A) or six (B) recurrent weeks (excluding winter and Easter holiday periods). The sessions were organized at the school premises as a part of a normal school-day and a teacher of the class was present during all times. The language of the project was Finnish.

The central theme of the workshops was to design a "digital pal" - a future omnipotent robot or gadget for helping and entertaining school children. The overall structure was similar to all participating groups, starting from fieldwork and ideation, and continuing to design and programming phases. However, the duration of the workshops and tasks in each phase were adjusted according to the age and grade level of the children, for example field work task of interviewing other pupils was only conducted with 4th graders in project $\mathrm{B}$. Both projects culminated in an ending event at the university where the project was wrapped up and the university Fab Lab (digital fabrication laboratory) was introduced to the children.

All sessions started with a recap of the tasks already done in the project and a short introduction to the current topic and how it relates to the actual design process. Researchers sent their materials to the teachers before each session and the teachers were free to modify and comment on the plans. The materials were implemented by researchers after conversations with the teachers. The idea was that the teachers would get to know the materials beforehand and lead the sessions while learning the processes together with the children; the implementation was such fully only in project $B$ and partially in project $A$, however.

Project $C$ was conducted with 9th grade pupils (age 14-15 years). The official language of the project was English, but the pupils communicated with each other in Finnish language and used also Finnish in the interviews. The project consisted of 10 sessions arranged within two-week time frame, with 4-6 sessions per week. The sessions were organized partially at the school and partially at the university premises including the university Fab Lab. The structure of the project was different in comparison with the first two projects; as requested by the teacher, this one concentrated more on entrepreneurship and generating business ideas. The field study phase was replaced by forming a business plan and conducting relevant background research. The whole project ended up with pitching the business ideas for the whole class and for a Shark Tank group of investors (researchers) voting for the best idea.
Two researchers observed and participated in all the workshops of the first two projects. The third project was conducted by 3 - 5 researchers present in each session. Field notes were taken in most of the sessions and situations were also video recorded. During the projects, the pupils generated many types of material such as concept pictures, scenario texts, drawings, as well as 3D models using TinkerCad. In projects A and B, the children got notebooks at the beginning of the project, and they were used for conducting most of the tasks. The notebooks were collected after the final session. In project $C$, the pupils also generated business idea presentations. Finally, the pupils who gave a research permit were interviewed. Younger pupils in project A and B were interviewed in groups of 3-6 pupils by one researcher. The older pupils in project $C$ were individually interviewed by two researchers.

In the first phase of data analysis, three researchers started to go through the outcomes of all projects and got interested in the difficulties some children had regarding who they were actually designing and making for. All of the three researchers analyzing the data participated in the project planning and one of the researchers participated also in running the project workshops with children and collecting the data. Despite our careful planning of the projects and the methods used, some confusion appeared among the pupils as to what was the actual target of their work. In the next phase, we collected from the data all occurrences related to why certain methods were chosen to be taught to children, what was the design goal, why, and to whom were the children's final designs and products meant for. The analysis results were extensively discussed among the authors to ensure that they agreed with the interpretations. At the end, the Finnish research material (e.g. interview quotes and concept pictures) was translated into English in the paper writing stage. Finally, Table 2 of this paper was created, to make the differences in design goals visible.

\section{ANALYSIS}

The original idea in the projects A and B was to try out different types of field work methods for data gathering before the ideation phase. Some methods were adapted from user-centered design tool palette concentrating on understanding other people, future users, and their needs (interviews, observation) while other methods (cultural probes study) were more about understanding and analyzing one's own needs in participatory design style and thus giving inspiration for the ideation and design phase. Project $C$ started with 


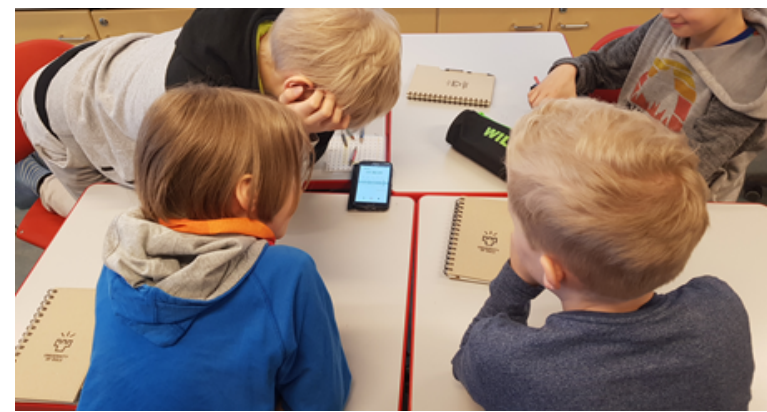

Figure 1: Pupils listening and analyzing interview material.

generating a business idea to fulfil a need of a customer. Next, we describe the insights gained and challenges faced during this process.

\subsection{Designing for others}

The first task for the pupils in the workshops (A, B) was to observe the fellow pupils at school. The pupils were given example questions to focus on in the playtime break:

- What are your school mates doing during playtime?

- With whom they are doing it?

- Where are they doing it?

- What kind of games are played?

- What kind of toys are used?

The ultimate focus was set to find spots were a "digital pal," a possible omnipotent future robot or gadget would be needed. The pupils were asked to write down their observations to notebooks or record them using their phones.

The second data gathering method was interviewing fellow pupils. The possible question examples were:

- What kind of digital friend would you want to have and why?

- How would your digital friend look like?

- What would it be able to do?

Again, pupils were asked to record the findings either by writing them down to their notebooks or by using the voice recorder of their phone.

The observations were conducted during a normal playtime break at the school yard. Children were set in small groups before the assignment and the idea was to conduct the observations in groups (A) or in pairs (B). In project A, the groups were supported by one approximately 14 -year-old supervisor pupil. Children made a number of interesting observations such as: noticed what children were playing (e.g. football, basketball, tag, toboggan), spotted situations where children were laughing with each other or teasing others, and counted the sizes of the formed groups (4- 8 boys playing football, 8-10 girls playing tag). Observations of the surrounding environment were also made.

In Project B interviews were conducted within the classroom. The idea was that each group of 4-5 children conducts the interviews with children from other groups (See figure 1). The child groups gathered the following user requirements through the interviews with fellow pupils: Digital pal should be a cheerful and tranquil robot dog, a sporty and cute dog, a boy, a pet, it should be able to fly, and it should be able to launch an Xbox. Four groups out of six described that the interviewees had desired for an animal-shaped digital pal.

The idea of the field studies described above was to collect user needs and ideas from others for further development in ideation and design phase and this was explained to the children before the field studies. However, according to the end interviews with the pupils, reason for why the observations were conducted in the first place remained obscure for most. Although some liked the observing task, others considered it rather "unpleasant" and most did not understand the connection between observing people and designing: "I wondered why we did the observing if we just code and do stuff like that. That what do we need it for." (Girl 4th grade)

Concerning the interviews, same reaction was noticed. "Well I was wondering that if we did coding and programming with the computer and 3D-modelling and then suddenly went interviewing. I was just wondering that." (Boy 4th grade). On the other hand, although the interviews were conducted and recorded properly, utilizing the interview results in the later phase was forgotten, and children's own ideas outdid the collected field data: "Well they talked about a robot and Aleksi* said that it would be able to play Fortnite and Oskari said that it should be able to switch on the Xbox [interviewer: I assume your design was not like that at the end?] No (shaking head)" (Girl 4th grade) (" names changed for anonymization)

\subsection{Designing for myself}

The third field study method was a probe study using "idea boxes." Pupils decorated a small cardboard box using pipe cleaners, stickers, feathers, craft eyes etc. (See figure 2). After crafting the probe pupils were asked to carry the probe with them after school. The instructions were as follows: "Carry the "idea box" with you imagine the box is your friend. Take pictures of the box in different situations, write and draw what you would do with it in different situations if it were your "digital pal"." As the task of ideating with the decorated probe was an extra homework, not all the pupils conducted it. The pupils of the first project were especially advised to write notes in their notebooks about where they took the probe and what they imagined that it would have done in those situations. The 4th grade pupils of the second project were asked to take pictures of the probes in different situations.

The probe task inspired the children and the probe had been taken to different occasions. Pictures were also taken with the probes, but they were not included in the research data. Probe was taken for example to: home, a car, a forest, a cottage, a basketball tournament, skiing, and a community center. Children also described several activities they had done with the probe such as: make a hut, making a snack, sleep. After carrying the probe to different places and activities some children also described what they wished the digital pal would have done in different situations. For example: cheering in basketball game, taking dishes after breakfast, adjusting the radio in the car, steeling sweets from a grocery store, driving a car and bicycle, playing with Barbie dolls and slime, feeding pets. Surprisingly, the children also disagreed with their digital pal probes which did not do what was wanted as in the following citations: "It did not help me when I got stuck in a pile of peat" (Boy, 


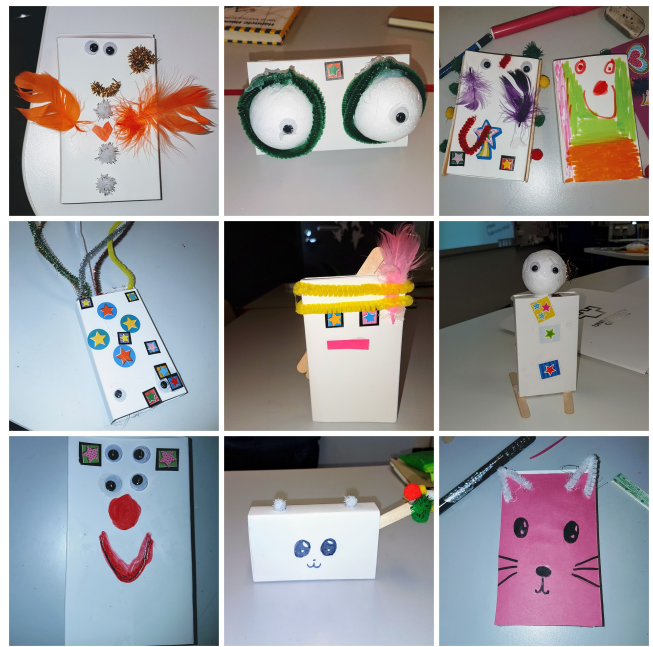

Figure 2: Examples of the "idea box" probes crafted by children in projects $A$ and $B$

project A) "When I was making an omelet. It did not participate. I got mad at it and left." (Girl, project A)

The designs formulated by the probe study were heavily concentrated on children's own surroundings outside of school environment. The needs the digital pal would fulfil were personal and particular, and ideas varied greatly from cheering in a game to a cook assistant. Ideas were also controversial and provocative (such as steeling sweets).

After the field work phase the actual designing of the digital pals started by drafting concept pictures and scenarios, after which the concepts were 3D modelled with play dough. The designed concepts looked like cute pets or funny characters with super abilities (See figure 3). The abilities of the digital pals of the first type were for example: makes the day, you can hug it, can talk with humans and cats, can help, can play Trouble. For the latter ones, the abilities were: can play, can shoot laser, can save people, or generates candy or soda. Children considered also "technical aspects" of the digital pal. Several concept pictures included inputs for a charger, power, and volume buttons as described in a concept description of a 4th grader: "This is a digital pal, who lives inside slime. A wire comes from the can and it charges the digital pal."

The digital pals' designs were created through concept pictures, play dough 3D models and scenarios. The user needs behind the digital pal designs were more general and vague (makes a day, can be hugged) than the needs found through the probe study. The children's designs also reminded each other more. It seemed that in project $\mathrm{B}$ the designs were based slightly on the interview material. As described in the earlier section, many of the pupils wished for an animal-shaped digital pal. Whereas interview findings were somewhat followed in design phase, the observational findings were entirely forgotten when the children started to form the designs. In project $\mathrm{A}$, the pupils did not conduct interviews at all.

\subsection{Designing for business purpose}

Designing for business might start from designing for oneself, with the initial idea originating from designer's own need, but the idea of designing for others who would use the product and would even be willing to pay for it as a customer, requires different kind of thinking. With this perspective, there is also an assumption that you are planning to benefit from the innovation somehow. The business purpose of the designs was highlighted with 9th graders in project $\mathrm{C}$.

The 14 - 15-year-old pupils in project $C$ were asked to ideate new business in the first session. They were told that to have a good business idea, it is necessary to have a customer who wants to pay for the product or service. Thus, it is essential to come up with a customer need or a problem that the product or service fulfills. The instructions guided the pupils to find ideas for example by thinking of a) everyday problems (e.g. waking up too late and not having time to eat breakfast), b) customer problems (e.g. healthcare / mental health problems: it takes too long to get professional help for the problems), c) non-customers (e.g. music industry \& people that don't listen to music), d) combine industries (e.g. healthcare and music industry). This introduction guided the pupils to start to think about other people and their requirements and needs. The idea was to think "how to make the world a better place" through the business ideas.

The ideation session was followed by background research sessions where the pupils were advised to study their idea from different perspectives and start to form a business plan. The idea was to map for instance possible competitors and to get an idea of possible future users. The pupils were also asked to conduct quick interviews with other people, possible future customers, and hear what they thought about the business idea. After background research phase, the pupils started to design their product through sketching and modelling. This was followed by digital fabrication and Making sessions where the pupils were advised to make a prototype or some part of it with the means of digital fabrication at the university FabLab. Finally, the groups pitched their ideas in a "shark tank" organized as final event for the project where "possible investors" (university staff members who were not involved in running the project) asked clarifying questions and gave constructive feedback for the groups (See Figure 4).

The pupils worked in groups of 4-5. During the project, the groups came up with the following ideas:

- A chair for improving your posture

- A hoodie with a neck pillow

- A safe pack -backpack

- A drone for delivering shopping items

- A reflecting necklace

The pupils explained in the end interviews quite vaguely how they came up with the business ideas, but the customers and their needs were explained in the pitching presentations. For example, reflecting necklace was targeted for youngsters: "We think that youngsters nowadays don't use reflector vests because they think it looks stupid on them. Our solution is a reflecting necklace and earrings that loos cool and Youngsters will use them." (project C, group 5). 

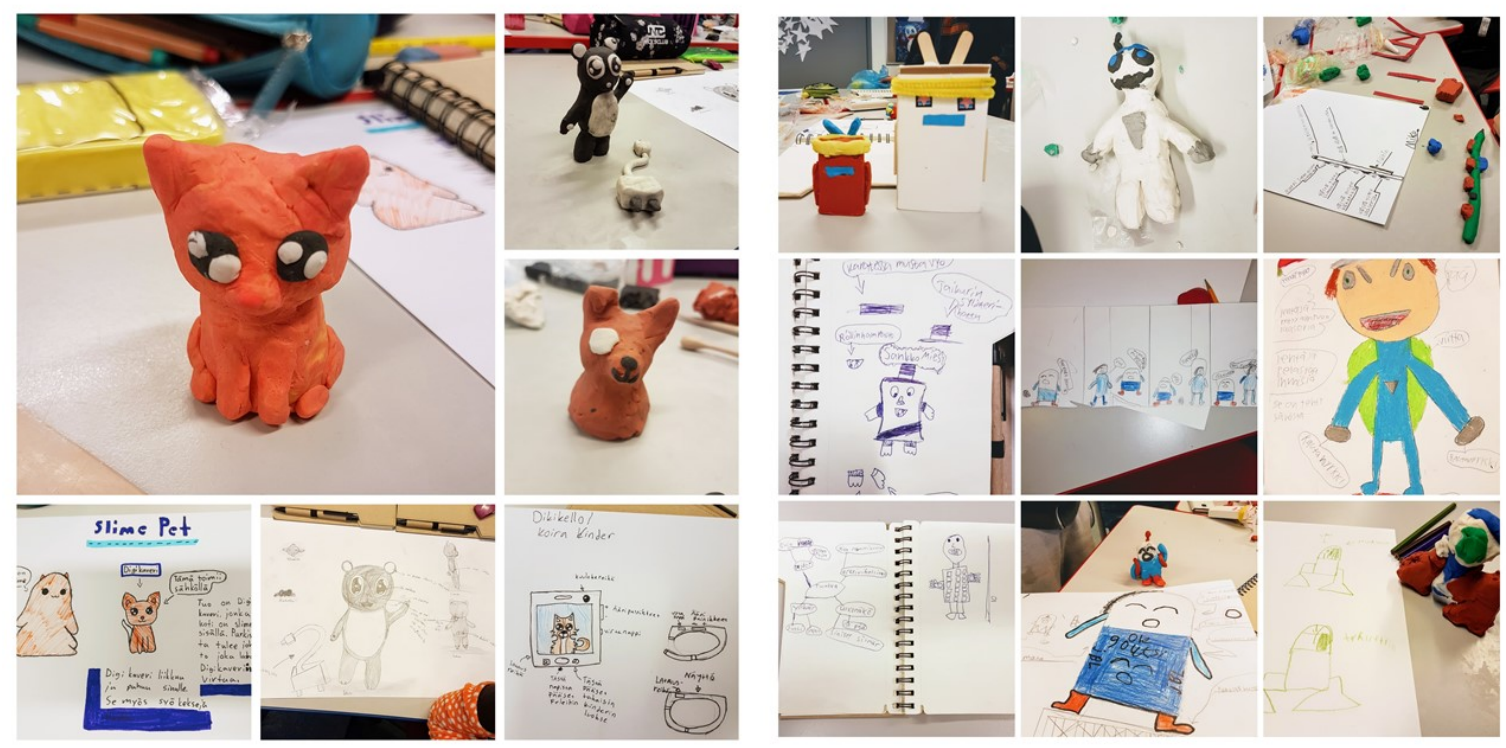

Figure 3: LEFT. Example 'cute pet' concept pictures and corresponding playdough 3D-models of the digital pal in project B. RIGHT. Example 'funny character' concept pictures, scenarios and corresponding playdough 3D-models of the digital pal in project $B$.

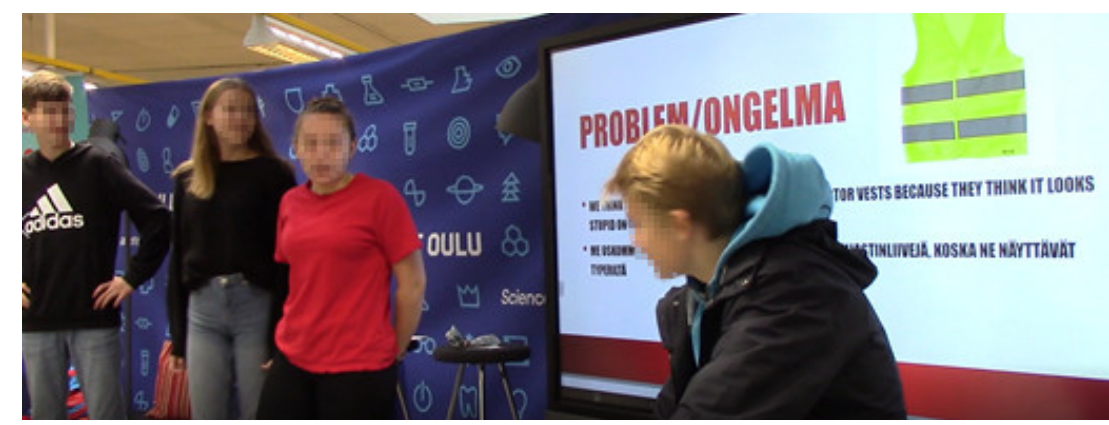

Figure 4: Pupils in project $\mathrm{C}$ pitching their business idea for the audience.

Although business aspects were not highlighted in projects $\mathrm{A}$ and $\mathrm{B}$, interestingly a couple of pupils came up with business ideas derived from the project tasks. These ideas related more to Making in general than to the design of the digital pal itself: "We could make images with Tinkercad and then make them with the machine and sell them and we would get money with that job. And then we could go for some trip with [other teacher's] pupils and our pupils." (Pupil, Project A) "I would probably make phone covers and some keyrings and then I would sell them in the street market." (Pupil, Project B)

\section{DISCUSSION}

Previous literature has highlighted the importance of teaching children design and Making skills. The aim of the current paper was to make visible the embedded assumptions in the design and Making projects in the context of children's education. We contribute on top of previous research by highlighting how one of the issues where these assumptions become visible is the design goal - who are we designing for and for what purpose, and by proposing a categorization for understanding this diversity. We discuss the diversity and related challenges as well as present a categorization for mapping the diversity.

\subsection{Diversity in Design and Making}

There is a lot of variety in the existing CCI research combining design and Making. There is a strong literature base on inviting children to engage in user-centered or participatory design or Making in adult-initiated and-facilitated projects, but there is also emerging literature on integrating design and Making into children's education, with strong focus particularly on Making in education. The approaches utilized in involving children in design and Making in 
CCI research - user-centered design, participatory design, Making, and entrepreneurship education - have fundamental differences between how they approach who is the target and what is the goal of design and Making. User/human centered and participatory design advocate the idea of empathizing with and designing for and with a user, who is seen as separable from the designer. Some work in the CCI research inviting children to empathize with and design for someone else could already be identified. The Maker movement, then again, relies on DIY Makers solving their own problems and serving their own needs through Making, even if at the same time engaging with and contributing to the wider community. A lot of Making projects with children have been conducted along these lines in CCI research. Additionally, through our review of the existing literature, we recognized that Making is nowadays also closely associated with business and entrepreneurship and hence geared towards designing for the customer willing pay for the solution. Such projects addressing entrepreneurship education in CCI were also found. Overall, our literature review revealed that Making in education mixes and matches a variety of approaches and philosophies: designing for a user, Making for oneself, Making for science learning, and designing or Making for a community or a customer.

In our own projects, it was challenging for children to make the difference. During these carefully prepared projects, various frustrations and confusions arose. We revealed some successes but also several challenges among children in understanding the design process and conflicts between designing for oneself versus designing for others. Designing for oneself seems to be a reasonably clear concept. The children utilized the cultural probes method and with it ideated several usages for the digital pal. This entailed designing for oneself, which seemed to work quite well, even if some children ended up getting mad at the box they carried with them, showing a deep engagement with the box, while also a slight misunderstanding of the task.

Designing for others seems to be a surprisingly difficult concept for pupils to understand and execute. Despite our careful preparation of the process and material for the projects, the participating children had difficulties in understanding who they were actually designing and Making for. The interview and observation methods turned out to be difficult for the children: some considered using them as unpleasant and many reported of not understanding their purpose. Our findings also indicate that it was challenging for children to utilize the material collected through different field study methods. Other people's needs and desires concerning the concept were overridden with pupils' own ideas and desires. With the younger children, their cognitive development might partially explain these difficulties (see e.g. [17]), but this was challenging for all the participating pupils despite the age group. There were various reasons contributing to this confusion, but a central one was revealed through the analysis for this paper: it was challenging for the children to take the implicit leap from considering their own needs, on the one hand, to designing for more general 'users' and coming back to Making for themselves again (projects A and B), and on the other hand, to designing and Making for paying customers (Project C). Although in Project $\mathrm{C}$ the task itself (generate a business idea) guided the $9^{\text {th }}$ graders to consider others in the design phase, it was still not as simple for them as we expected, and most of the business ideas were drawn from the design group's own needs. User studies were not meaningful for them at all and only some of the groups conducted interviews with potential future customers. Overall, we maintain that combining a user-centered design process with Making - with or without the entrepreneurial aspects - can be challenging and might not happen naturally.

An additional layer, business orientation (in our Project $C$ ), may confuse even more the target and goals of the design. We argue, however, that business orientation is an important aspect if we want children to grow to the digital innovators of the future [23] hence it is not enough that children learn only design and Making skills. CCI designers should embrace the possibility to help children grow not only to be designers of new technologies for others or Makers of meaningful objects for their own use, but entrepreneurs instead, the innovation powerhouses of the future, dreamers who change the world through their businesses. For this, we need to teach children also entrepreneurship skills, to add in their toolbox business understanding, enabling them to see that in addition to themselves or 'users' there are also 'customers' who need to be willing to pay for the new innovation, i.e., the innovation needs to bring value (see e.g. [7], [28]) for the paying customer. The business/product understanding is a very natural addition to design and Making projects, but, once again, the researchers need to be clear in their communication regarding the target group for the outcome.

The HCI literature has for long argued that in the development of digital technology, it is critical to differentiate between handson users and paying customers - too often the paying customers are listened to instead of users. Moreover, the HCI literature has pointed out decades ago that designers tend to design for themselves and the like-minded, whereas they should learn to empathize with users, who usually are distinctly different from the designers. HCI methods aim to enable empathy through personas and such. Overall, it is not a surprise that children in our projects had difficulties in making the difference between designing for oneself and designing for others, considering all these challenges even among the adults.

One aspect not explicitly addressed in our projects but mentioned in the literature is Scandinavian participatory design inspired design and Making with children with heavy emphasis on ethical and political aspects. So far, not too many projects have empirically explored this type of design and Making with children ([25] as a notable exception), but projects of this type have already been called for in the literature [24]. In such projects, a critical approach to design and technology should be adopted, the status quo critically scrutinized, and the empowerment of people considered as the design and Making goal.

\subsection{A Categorization for Mapping the Diversity}

We argue that CCI researchers and practitioners working in the context of children's education should carefully consider the question of who the children are asked to design and Make for. On the one hand, it helps in setting learning goals for the projects as well as in methodological choices for them. On the other hand, certain methodological choices have also design and Making goal related issues embedded in them, which is useful to acknowledge. We propose in Table 2 an initial categorization of goals in design and 
Table 2: Categorization of the diverse goals in design and Making projects and position of our projects in the categorization.

\begin{tabular}{|c|c|c|c|c|}
\hline \multirow[b]{2}{*}{ Beneficiary } & \multicolumn{4}{|c|}{ Goal of design and making } \\
\hline & Personal good & Common good & Business & Education of other subjects \\
\hline \multirow[t]{4}{*}{ Myself } & Project A & Project B & Project C & Project A, B, C \\
\hline & -- & -- & -- & -- \\
\hline & Do-It-Yourself; & Do-It-Yourself; & Do-It-Yourself; & Learning new skills when \\
\hline & $\begin{array}{l}\text { Creating useful } \\
\text { designs / objects for } \\
\text { personal use } \\
\text { [e.g. 27] }\end{array}$ & $\begin{array}{l}\text { Creating useful designs / } \\
\text { objects for personal use as } \\
\text { well as for the likeminded } \\
\text { community [e.g. 16] }\end{array}$ & $\begin{array}{l}\text { Creating useful designs / } \\
\text { objects for personal use but } \\
\text { building business around it } \\
\text { [e.g. 4] }\end{array}$ & $\begin{array}{l}\text { creating personally } \\
\text { meaningful objects } \\
\text { [e.g. 27] }\end{array}$ \\
\hline \multirow[t]{3}{*}{ Others } & \multirow{3}{*}{$\begin{array}{l}\text { Personal satisfaction } \\
\text { through helping others } \\
\text { (voluntary work, } \\
\text { charity) }\end{array}$} & \multirow{3}{*}{$\begin{array}{l}\text { Participatory design, } \\
\text { community informatics; } \\
\text { Value creation for society or } \\
\text { a community } \\
\text { [e.g. } 42 \text { ] }\end{array}$} & Project C & Project B, C \\
\hline & & & -- & -- \\
\hline & & & $\begin{array}{l}\text { Value creation for paying } \\
\text { customers }\end{array}$ & $\begin{array}{l}\text { Learning new skills when } \\
\text { creating objects useful for } \\
\text { common good } \\
\text { [e.g. } 42]\end{array}$ \\
\hline
\end{tabular}

Making projects for CCI researchers for revealing and addressing the diversity involved in teaching children design and Making. The categorization is drawn from the previous literature and informed by our empirical insights. Our own design and Making projects are used as illustrative examples in the categorization.

The categorization in Table 2 identifies various goals for design and Making. The categorization makes visible how projects may aim at designing and Making various kinds of objects and tools either for the designers and Makers themselves or for a larger community or the entire society (cf. [57]). Then again, they can be harnessed for building business: this may happen accidentally, if the like-minded get excited about the tools developed, but this can also be intentionally aimed at from the very beginning of the project.

This categorization is particularly designed for researchers and practitioners interested in technology, design, and STEM education of children, for whom educating future designers and Makers should be seen as among top priorities. For such an education, it is critical to enable children to see and reflect on who the beneficiaries of the designed and Made objects will be. Important here is to note that design and Making are indeed often associated with technology, STEM and science education, while obviously a multitude of subjects can be integrated, including arts, social sciences and humanities. This categorization does not cover the learning goals of these subject matters, while we think this categorization is useful also for researchers and practitioners working with these subject matters, in the context of design and Making projects with children. Learning is intermingled with any project where children design and Make: children gain a variety of skills and abilities, including skills around design and Making, when engaging with them. Hence, for any project it is useful to consider what children will learn along the way.

Our projects had the goal of design and technology education, while at the same time we can say that in Project A, the children concentrated on personal good and designed for themselves, in Project $\mathrm{B}$ the design took more into account the like-minded peers, whereas in Project $C$ the target group of the business ideas were the pupils themselves as well as others. In Projects A \& B the field study methods aimed partially to collect ideas from peer pupils, i.e. like-minded people, which could have fostered the design process to come up with ideas both for the designer her/himself and for her/his community (common good). However, in practice the developed ideas were heavily based on designers' own experiences and personal life.

In many projects in the CCI literature, it has been usual to invite children to design and Make personally meaningful objects and tools (e.g. [9], [23], [27]), in which case one is asked to design and Make for oneself (and the like-minded). However, in some projects it is more a choice what the researchers see as central from the point of view of the project goals. Thus, it is up to the researchers to contemplate what they wish to communicate to children about design and Making goals: whether they wish to emphasize oneself or the others (users, customers, communities, society) as the primary beneficiary. Overall, we see that in the current work combining design and Making in education (e.g. [23], [25], [48]) as well as combining Making and entrepreneurial education ([14], [49]) design and Making are seen as vessels for serving something else than purely the individual provided with practical tools: they advocate empowerment, agency, entrepreneurship. Thus, design and Making serve a higher goal than just learning the practical skills. Children are nevertheless engaged in practical design and Making activities during which they implicitly or explicitly are designing and Making for someone or something. It is better for us to articulate the agenda and aims for children rather than leave them alone to make their own interpretations and remain confused. To help the articulation, we have formed the categorization presented in Table 2. The categorization can be utilized for positioning research and for articulating it to the participants of the design and Making projects.

Summing up, we argue that it is important to make the conceptual differences clear. It is easy to say this, but we know from the long and challenging history of $\mathrm{HCI}$ in industry as well as in 
education of adults that these differences are not always easy to internalize. Designers easily resort to designing for themselves. Especially for children, designing for common good and for others is challenging - this requires empathy, and building of empathy towards users is not a trivial task even with adults (see also [48], [49]).

\section{CONCLUSION}

Previous literature has highlighted the importance of teaching children design and Making skills for gaining valuable skills for the future. In this paper, we have identified differences between participatory and user-centered design, Making philosophy, and entrepreneurship education, concerning who is the user we are designing and Making for. While user-centered and participatory design philosophies highlight understanding and empathizing with the user, Making often starts from the idea of creating things for one's own needs. We illustrated challenges associated with this diversity through three design and Making projects with children, conducted with three different level school classes. We revealed challenges among children in understanding the design process and conflicts between designing for oneself versus designing for others. We also proposed a categorization for handling the conceptual differences in projects engaging children in design and Making. We believe that researchers and practitioners should make these conceptual differences clearer in their own work and with children.

As combining design and Making in education is currently advocated [48] as well as combining Making and entrepreneurial education [14], [49], we see that addressing this diversity is a very current and relevant issue for the CCI community. The assumptions embedded in different approaches and methodologies both limit what we can teach children in design and Making projects as well open us different possibilities for that. CCI researchers should more consciously and explicitly address this diversity in their projects with children in the context of their education. CCI researchers do not possibly articulate this clearly enough in their projects; at least they do not explicitly mention it in their papers. In some cases, when the work addresses e.g. community development or solving societally relevant problems, it is quite obvious that the children should not be only designing for themselves but consider the needs of a community or the society even (e.g. in [2], [25], [42], [46], [55]). However, in many studies addressing Making and the Maker movement together with children, this may remain quite unclearly articulated. Intertwinement of the design goals and chosen methodologies should also be made more visible: on the one hand, with certain goals some methodologies can be more fitting than others on the other hand, by making certain methodological choices, we commit to certain goals.

This study has limitations. We examine only three projects conducted with children in one particular country and city in this study. In future research, a larger number of projects conducted in different contexts might reveal new understanding on the topic. Additionally, in our projects examined in this paper, we could have articulated better the differences between design goals and targets in our teaching material. In the future, empirical studies utilizing the categorization proposed in this study should be carried out: the categorization should help in articulating the design goals and targets better for the participating children. Moreover, we analyze in this study only the design/making goal as an embedded assumption in the methodological choices; more of similar kind of assumptions and their effects could be analyzed in future studies. Finally, this study focused on technology and STEM education of children. Future studies are needed on children's actual learning processes and outcomes

\section{ACKNOWLEDGMENTS}

This study was funded by Finnish cultural foundation, North Ostrobothnia regional foundation.

\section{REFERENCES}

[1] Bekker, M., Julie Beusmans, David Keyson, Peter Lloyd, KidReporter: a user requirements gathering technique for designing with children, Interacting with Computers, Volume 15, Issue 2, April 2003, Pages 187-202, a

[2] Bekker, T., Bakker, S., Douma, I., Van Der Poel, J., Scheltenaar, K. (2015). “Teaching children digital literacy through design-based learning with digital toolkits in schools." International Journal of Child-Computer Interaction 5, September, 29-38.

[3] Blikstein, P. 2013. Digital fabrication and 'making' in education: The democratization of invention. In FabLabs: Of machines, makers and inventors J. WalterHerrmann and C. Büching (Eds.), 1-21

[4] Browder et al. 2014 ->Browder, R. E., Aldrich, H. E., \& Bradley, S. W. (2017, January). Entrepreneurship research, makers, and the maker movement. In Academy of Management Proceedings (Vol. 1, p. 14361). Briarcliff Manor, NY 10510: Academy of Management.

[5] Chu, S. L., Quek, F., Bhangaonkar, S., Ging, A. B., \& Sridharamurthy, K. (2015). Making the Maker: A Means-to-an-Ends approach to nurturing the Maker mindset in elementary-aged children. International Journal of Child-Computer Interaction, 5, 11-19.

[6] Chu, S. L., Schlegel, R., Quek, F., Christy, A., \& Chen, K. (2017, May). 'I Make, Therefore I Am' The Effects of Curriculum-Aligned Making on Children's Self-Identity. In Proceedings of the $2017 \mathrm{CHI}$ Conference on Human Factors in Computing Systems (pp. 109-120).

[7] Cockton, G. (2006). Designing worth is worth designing. In: NordiCHI'06. Proceedings of the 4th Nordic conference on Human-Computer Interaction, Oslo, Norway, October 14-18, 2006. ACM, pp. 165-174.

[8] Dougherty, D. (2012). The maker movement. Innovations: Technology, Governance, Globalization, 7(3), 11-14.

[9] Dreessen, K., \& Schepers, S. (2019). Foregrounding backstage activities for engaging children in a FabLab for STEM education. International Journal of ChildComputer Interaction, 20, 35-42.

[10] Druin, A. (1999, May). Cooperative inquiry: developing new technologies for children with children. In Proceedings of the SIGCHI conference on Human Factors in Computing Systems (pp. 592-599).

[11] Druin, A. (2002). The role of children in the design of new technology. Behaviour and information technology, 21(1), 1-25.

[12] Durães, D.A. (2015). "Gaming and Robotics to Transforming Learning." Methodologies and Intelligent Systems for Technology Enhanced Learning, 51-56.

[13] Eriksson, E., Torgersson, O., \& Melin, A. (2018, June). Plan\&do: a technology probe supporting children with intellectual disabilities in leisure activities. In Proceedings of the 17th ACM Conference on Interaction Design and Children (pp. 663-668).

[14] Fraunhofer, Elisabeth; Voigt, Christian \& Schön, Sandra (2019). Towards a Model of Early Entrepreneurial Education: Appreciation, Facilitation and Evaluation. In Di Mascio, T., Vittorini, P., Gennari, R., De la Prieta, F., Rodríguez, S., Temperini, M., Azambuja Silveira, R., Popescu, E., Lancia, L. (Eds.), Methodologies and Intelligent Systems for Technology Enhanced Learning, 8th International Conference (pp. 139-146), retrieval date, from https://link.springer.com/book/10.1007\%2F9783-319-98872-6.

[15] Gershenfeld, N. (2005). Fab: The coming revolution on your desktop-From personal computers to personal fabrication. New York: Basic Books.

[16] Geser, G., Eva-Maria Hollauf, Hornung-Prähauser, V., Schön, S., \& Vloet, F. (2019). Makerspaces as social innovation and entrepreneurship learning environments: The DOIT learning program. Discourse and Communication for Sustainable Education, 10(2), 60-71. doi:http://dx.doi.org/10.2478/dcse-2019-0018

[17] Ginsburg, H. P., \& Opper, S. (1988). Piaget's theory of intellectual development (3rd ed.). Englewood Cliffs, NJ, US: Prentice-Hall, Inc.

[18] Gould, J. D., \& Lewis, C. (1985). Designing for usability: key principles and what designers think. Communications of the ACM, 28(3), 300-311. 
[19] Greenbaum, J., \& Kyng, M. (1992). Design at work: Cooperative design of computer systems. L. Erlbaum Associates Inc.

[20] Guha et al. 2014 ->Guha, M. L., Druin, A., \& Fails, J. A. (2013). Cooperative Inquiry revisited: Reflections of the past and guidelines for the future of intergenerational co-design. International Journal of Child-Computer Interaction, 1(1), 14-23.

[21] Hanna, L., Risden, K., \& Alexander, K. (1997). Guidelines for usability testing with children. interactions, 4(5), 9-14.

[22] Hatch. M. 2014. The Maker Movement Manifesto. McGraw-Hill Education, New York.

[23] Iivari, N., \& Kinnula, M. (2018, August). Empowering children through design and making: towards protagonist role adoption. In Proceedings of the 15th Participatory Design Conference: Full Papers-Volume 1 (pp. 1-12).

[24] Netta Iivari and Kari Kuutti. 2018. Critical design in interaction design and children: impossible, inappropriate or critical imperative?. In Proceedings of the 17th ACM Conference on Interaction Design and Children (IDC '18). ACM, New York, NY, USA, 456-464. DOI: https://doi.org/10.1145/3202185.3202773

[25] Iversen, O. S., Smith, R. C., \& Dindler, C. (2017, June). Child as protagonist: Expanding the role of children in participatory design. In Proceedings of the 2017 Conference on Interaction Design and Children (pp. 27-37).

[26] Joshua G. Tanenbaum. Amanda M. Williams, Audrey Desjardins, Karen Tanen baum. 2013. Democratizing technology: pleasure, utility and expressiveness in DIY and maker practice. In Proc. of ACM CHI'13, pp. 2603-2612

[27] Katterfeldt, E. S., N. Dittert, and H. Schelhowe. 2015. Designing digital fabrication learning environments for Bildung: Implications from ten years of physical computing workshops. International Journal of Child-Computer Interaction 5, 3-10.

[28] Kinnula, M., Iivari, N., Isomursu, M., \& Laari-Salmela, S. (2018). 'Worksome but Rewarding'-Stakeholder Perceptions on Value in Collaborative Design Work Computer Supported Cooperative Work (CSCW), 27(3-6), 463-494.

[29] Kinnula, M., Iivari, N., Molin-Juustila, T., Keskitalo, E., Leinonen, T., Mansikkamäki, E., ... \& Similä, M. (2017, December). Cooperation, Combat, or Competence Building - What Do We Mean When We Are'Empowering Children'in and through Digital Technology Design?. In ICIS.

[30] Kouprie M. \& Froukje Sleeswijk Visser (2009) A framework for empathy in design: stepping into and out of the user's life, Journal of Engineering Design, 20:5, 437-448, DOI: 10.1080/09544820902875033

[31] Lindtner, S., G. D. Hertz and P. Dourish. 2014. Emerging sites of HCI innovation hackerspaces, hardware startups \& incubators. In Proceedings of the SIGCHI Conference on Human Factors in Computing Systems. ACM, New York, 439-448.

[32] Lindtner, S., Bardzell, S., \& Bardzell, J. (2016, May). Reconstituting the utopian vision of making: HCI after technosolutionism. In Proceedings of the $2016 \mathrm{CHI}$ Conference on Human Factors in Computing Systems (pp. 1390-1402). ACM.

[33] Gulliksen, J., Göransson, B., Boivie, I., Blomkvist, S., Persson, J., \& Cajander, Å (2003). Key principles for user-centred systems design. Behaviour and Information Technology, 22(6), 397-409.

[34] Ohlmeier, B. (2013). Civic education for sustainable development. Discourse and Communication for Sustainable Education, 4(1), 5ñ22. Retrieved from https: //doi.org/10.2478/dcse-2013-0001

[35] Peppler, K., \& Bender, S. (2013). Maker movement spreads innovation one project at a time. Phi Delta Kappan, 95(3), 22-27.

[36] Pucci, E.L., Mulder, I. (2015). "Star(t) to Shine: Unlocking Hidden Talents Through Sharing and Making." Distributed, Ambient, and Pervasive Interactions, 85-96.

[37] Riekhoff, J., \& Markopoulos, P. (2008, June). Sampling young children's experiences with cultural probes. In Proceedings of the 7th international conference on Interaction design and children (pp. 145-148).

[38] Sawhney, N., Graver, C., \& Breitkopf, E. (2018, June). Audio journaling for selfreflection and assessment among teens in participatory media programs. In Proceedings of the 17th ACM Conference on Interaction Design and Children (pp. 93-105).

[39] Scaife, M., Rogers, Y., Aldrich, F., \& Davies, M. (1997, March). Designing for or designing with? Informant design for interactive learning environments. In
Proceedings of the ACM SIGCHI Conference on Human factors in computing systems (pp. 343-350)

[40] Schuler, D., \& Namioka, A. (Eds.). (1993). Participatory design: Principles and practices. CRC Press.

[41] Sheridan, K., Halverson, E. R., Litts, B., Brahms, L., Jacobs-Priebe, L., \& Owens, T. (2014). Learning in the making: A comparative case study of three makerspaces. Harvard Educational Review, 84(4), 505-531.

[42] Smith, R. C., Iversen, O. S., \& Hjorth, M. (2015). Design thinking for digital fabrication in education. International Journal of Child-Computer Interaction, 5 , $20-28$.

[43] Robertson, T., \& Simonsen, J. (2012). Participatory Design: An introduction. In Routledge International Handbook of Participatory Design (pp. 1-18). Routledge.

[44] Stangl, A., Kim, J., \& Yeh, T. (2014, June). 3D printed tactile picture books for children with visual impairments: a design probe. In Proceedings of the 2014 conference on Interaction design and children (pp. 321-324).

[45] Tanenbaum, J. G... Amanda M. Williams, Audrey Desjardins, Karen Tanenbaum. 2013. Democratizing technology: pleasure, utility and expressiveness in DIY and maker practice. In Proc. of ACM CHI'13, pp. 2603-2612

[46] Telhan, O., Kafai, Y. B., Davis, R. L., Steele, K., \& Adleberg, B. M. (2014, June). Connected messages: a maker approach to interactive community murals with youth. In Proceedings of the 2014 conference on Interaction design and children (pp. 193-196).

[47] Toombs, A., S. Bardzell and J. Bardzell. 2014. Becoming makers: Hackerspace member habits, values, and identities. Journal of Peer Production, 5, 1-8.

[48] Tuhkala, A., Wagner, M. L., Iversen, O. S., \& Kärkkäinen, T. (2019). Technology Comprehension-Combining computing, design, and societal reflection as a national subject. International Journal of Child-Computer Interaction, 20, 54-63.

[49] Unterfrauner, E., Christian Voigt, and Sandra Schön. 2018. Towards a model of early entrepreneurial education: appreciation, facilitation and evaluation. In Methodologies and Intelligent Systems for Technology Enhanced Learning, 8th International Conference, 139-146.

[50] van Doorn, F., Stappers, P. J., \& Gielen, M. (2013, April). Design research by proxy: using children as researchers to gain contextual knowledge about user experience. In Proceedings of the SIGCHI conference on Human Factors in Computing Systems (pp. 2883-2892)

[51] Van Holm, E. J. (2015). Makerspaces and contributions to entrepreneurship. Procedia-Social and Behavioral Sciences, 195, 24-31.

[52] Van Mechelen, M., Schut, A., Gielen, M., \& Klapwijk, R. (2018, June). Developing children's empathy in co-design activities: a pilot case study. In Proceedings of the 17th ACM Conference on Interaction Design and Children (pp. 669-674).

[53] Van Mechelen, M., Schut, A., Gielen, M., \& Södergren, A. C. (2019, June). Children's Assessment of Co-design Skills: Creativity, Empathy and Collaboration. In Proceedings of the 18th ACM International Conference on Interaction Design and Children (pp. 520-526).

[54] Von Hippel, E. (2005). Democratizing innovation: The evolving phenomenon of user innovation. Journal für Betriebswirtschaft, 55(1), 63-78.

[55] Weibert, A., Aal, K., von Rekowski, T., \& Wulf, V. (2015). " Hey, can we make that, please?": On Craft as a Means of Cross-cultural Community-Building. The Journal of Community Informatics, 11(2), 1-9.

[56] Ventä-Olkkonen L., Hartikainen H., Norouzi B., Iivari N., Kinnula M. (2019) A Literature Review of the Practice of Educating Children About Technology Making. In: Lamas D., Loizides F., Nacke L., Petrie H., Winckler M., Zaphiris P. (eds) Human-Computer Interaction - INTERACT 2019. INTERACT 2019. Lecture Notes in Computer Science, vol 11746. Springer, Cham

[57] Von Hippel, E. (1986). Lead users: a source of novel product concepts. Management science, 32 (7), 791-805.

[58] Klein, H., \& Myers, M. (1999). A Set of Principles for Conducting and Evaluating Interpretive Field Studies in Information Systems. MIS Quarterly, 23 (1), 67-93. doi: $10.2307 / 249410$

[59] Denzin, N. and Lincoln, Y. (2000) The Discipline and Practice of Qualitative Research. In: Denzin, N.K. and Lincoln, Y.S., Eds., Handbook of Qualitative Research, Sage, Thousand Oaks, 1-32. 